'Brighton and Sussex

University Hospitals, Brighton, UK

${ }^{2}$ Hurstwood Park

Neurosciences Centre,

Haywards Heath, West Sussex, UK

\section{Correspondence to}

Kapil Mohan Rajwani,

kapilrajwani@hotmail.com

Accepted 6 June 2014

\title{
Unusual and complex vertebrobasilar artery aneurysm
}

Kapil Mohan Rajwani, ${ }^{1}$ Panayiotis Koumellis, ${ }^{2}$ Sorin Bucur ${ }^{2}$

\section{DESCRIPTION}

Vertebrobasilar (VB) fusiform aneurysms are rare and it is uncommon for these aneurysms to present with subarachnoid haemorrhage (SAH). ${ }^{1}$ Only $3-4 \%$ of aneurysms in the posterior circulation arise at the $\mathrm{VB}$ junction. ${ }^{2}$ These lesions are extremely challenging to treat and are associated with high morbidity and mortality.

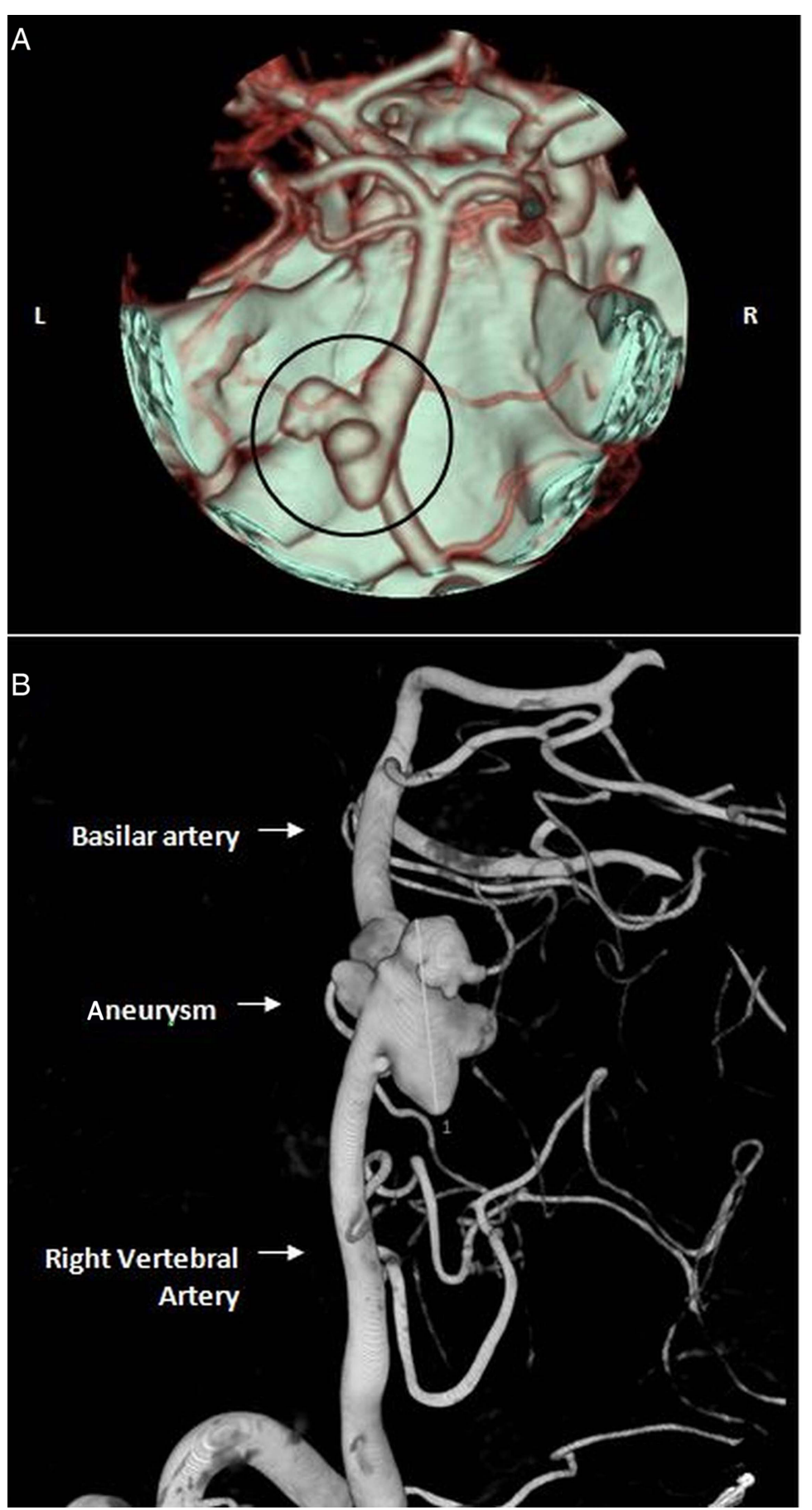

Figure 1 Three-dimensional images showing complex, multilobular, fusiform aneurysmal dilation of right vertebrobasilar junction. (A) CT and (B) cerebral angiography. 


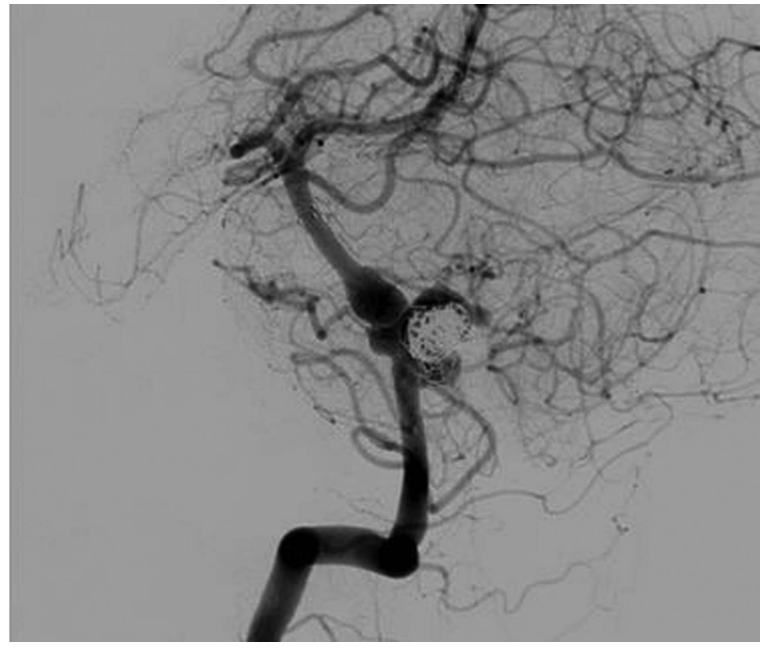

Figure 2 Cerebral angiography (postoperative day 9) showing coil embolisation of vertebrobasilar junction aneurysm.

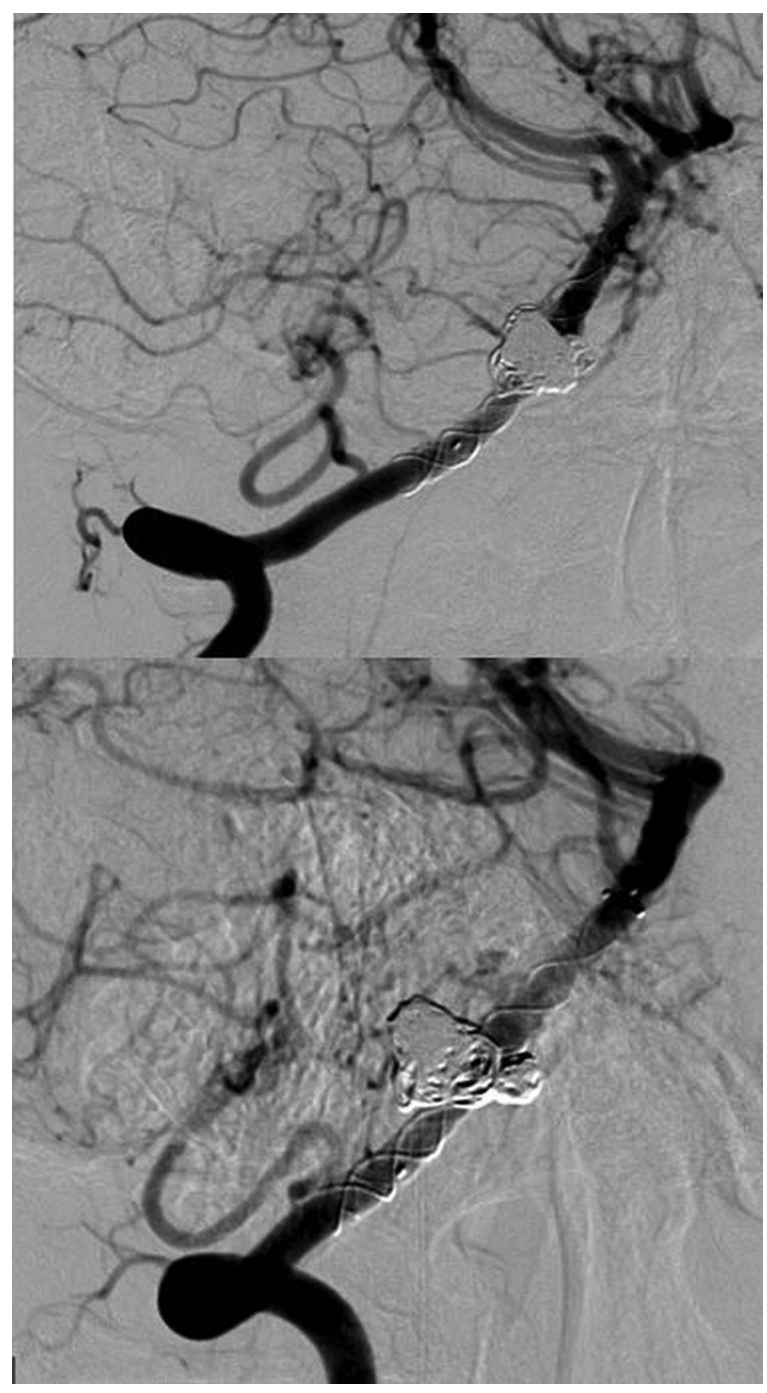

Figure 3 Follow-up angiography at 6 months showed complete occlusion of the aneurysm and the basilar artery lumen inside the stents appeared normal.
A 23-year-old woman presented with a 3-day history of sudden onset worsening occipital headache associated with neck stiffness and photophobia. CT of her head showed focal $\mathrm{SAH}$ in the posterior fossa. A subsequent CT angiography revealed a complex, multilobular, fusiform right $\mathrm{VB}$ junction aneurysm with ectasia of the proximal basilar artery (figure 1). The left vertebral artery was hypoplastic (normal variation).

After careful evaluation of treatment options, the patient underwent endovascular stent-assisted partial coil embolisation, with a view to further treatment with a flow-diverting stent after the acute phase. A cerebral angiography on postoperative day 9 confirmed the stent was in place, patent and there was no gross aneurysmal expansion (figure 2). The patient was discharged home 2 weeks postprocedure on antiplatelet therapy with a plan for close follow-up and further treatment.

Unfortunately, 1 day following discharge the patient sustained another SAH; she was readmitted at a different unit and underwent additional coiling of the residual aneurysm and two further stenting procedures (flow-diverting stent). She made an excellent recovery returning to full fitness. A follow-up angiography 6 months later showed the aneurysm was completely occluded and the basilar artery lumen inside the stents appeared normal (figure 3).

\section{Learning points}

- Spontaneous posterior circulation fusiform aneurysms are uncommon and more often found in younger patients. They may present with ischaemic symptoms, mass effect (eg, cranial nerve palsy) or intracranial haemorrhage.

- These lesions are difficult to treat surgically and carry a high operative morbidity and mortality. Endovascular coil embolisation is a useful alternative treatment modality.

- The risk of rebleeding is high in patients with vertebrobasilar fusiform aneurysms who present with subarachnoid haemorrhage. $^{3}$

Contributors KMR wrote the case report. PK and SB reviewed and edited the manuscript.

Competing interests None.

Patient consent Obtained.

Provenance and peer review Not commissioned; externally peer reviewed.

\section{REFERENCES}

1 Echiverri HC, Rubino FA, Gupta SR, et al. Fusiform aneurysm of the vertebrobasilar arterial system. Stroke 1989;20:1741-7.

2 Suri A, Mehta VS. Giant vertebrobasilar junction aneurysms: unusual cases. Neurol India 2003;51:84-6.

3 Tan LA, Moftakhar R, Lopes DK. Treatment of a ruptured vertebrobasilar fusiform aneurysm using pipeline embolization device. I Cerebrovasc Endovasc Neurosurg 2013;15:30-3 
Copyright 2014 BMJ Publishing Group. All rights reserved. For permission to reuse any of this content visit http://group.bmj.com/group/rights-licensing/permissions.

BMJ Case Report Fellows may re-use this article for personal use and teaching without any further permission.

Become a Fellow of BMJ Case Reports today and you can:

- Submit as many cases as you like

- Enjoy fast sympathetic peer review and rapid publication of accepted articles

- Access all the published articles

- Re-use any of the published material for personal use and teaching without further permission

For information on Institutional Fellowships contact consortiasales@bmjgroup.com

Visit casereports.bmj.com for more articles like this and to become a Fellow 